\title{
Quantifying the immeasurable: A reflection on sport, time and media
}

\section{Introduction}

In his seminal work, From Ritual to Record (1978), Allen Guttmann established seven distinguishing characteristics of modern sports in contrast with the primitive sporting manifestations. Among those characteristics, only the sixth and seventh, namely quantification and the quest for records, were genuinely modern since they had never appeared in any earlier stage of evolution while others were partly present in Greek, Roman or Medieval sports. In his view, modern sports embarked upon a numerical rush, in an attempt to measure and quantify immeasurable realities. From the perspective of the $20^{\text {th }}$ century, sport is always in the seek for more precise techniques, that is, new ways of certifying who is the best by means of measuring who is the fastest, the strongest and so forth - a purpose openly symbolized in the Olympic motto 'citius, altius, fortius'.

This desire for quantification constitutes an essential part of sport in modernity, and especially since the evolution and maturity of communication and media industries, has become a constant characteristic in the routines of modern citizens. In a critique on Guttmann's quantification concept, Giulianotti has highlighted the importance of measuring to 'reduce complex events into intelligible, manageable information for mass audiences' (Giulianotti 2005, 21). In order for the contemplation of sport to be meaningful to media consumers and spectators, it can no longer be reduced to an 'observational action', due to the sheer volume of knowledge that is required to fully enjoy and understand the spectacle.

The audiences both at home and in the stadia expect to gain instant knowledge on quantified variables such as the score, yellow cards (soccer); the points, rebounds, assists (basketball); the lap time, pit stops (Formula 1); the yards conquered (American football or rugby); the attempts made (jumps or throws in gymnastics, diving or track \& field); or the judging (figure skating or synchronized swimming), to name but a few. In recent times this experience of quantification has been enriched by second screens 
(D'Heer et al 2012) such as tablets and smartphones; devices that help the audience make sense of what is happening. As it might be expected in such measured environment, statistics can play an increasing role in providing information, perhaps most notably in baseball (Guttmann 1988). Data that is not necessarily perceived as significant by the casual consumer can be upgraded to relevant by means of technological aid, showing the unaware audience that something unique has occurred right before their eyes: a record-setting. All in all, it can be easily argued that records, the seventh concept proposed by Guttmann, function as climactic moments of quantification, the ultimate resources to determine the best ever.

This article aims to reflect on the concepts of quantification and records in contemporary professional sport from a time-centred and media perspective. This objective is based upon the assumption that sport is largely affected by a distinct time conceptualization, a conceptualization that lies at the heart of modern sport consumption and that determines the global appealing of sporting spectacles. In order to reveal that, firstly, the article provides the theoretical grounding by examining the implications that both quantification and records have for the standardization of elite sport. In that context, the text explores the consequences of the quantification process in the homogenization of sports, discussing the different spheres in which it develops such as the spatial homogeneity - the likeness of stadia, tracks or swimming pools-, and the ruling homogeneity — with the creation of supranational governing bodies that look after the application of analogous practice codes worldwide.

Secondly, the deeply embedded ideas of progress and ritual contained in the concept of sport are scrutinized while an 'evolutive definition of time' is proposed. Lastly, two opposite but complementary derivations of modern time conceptualization in sport are debated: the serialized time and the disrupted time, specially focusing on their implications for the mediated sport. Taken as a whole, the quantification serves the author as an instrument to comprehensively muse on relations between time, media and sport.

\section{Standardization of sport}


As a highly rationalized representation of modernity, one may argue that sport naturally tends towards quantification. In Brohm's opinion (1978) sport is a set of monotonous variations on a single theme whose mythology is based on measurable achievements: who is the strongest, the fastest...; magic barriers: who is the first one to...; and the matching up to the physical performance of animals. Later in the same book, Brohm adds that 'a commodity producing society develops universal tools of equivalence, evaluation and accounting' $(1978,72)$. Considered this way, progress in elite sport could be understood as the quest for new and more sophisticated means of observing and measuring this very progress. In this process the foundation of governing bodies that set up the rules of participation is central to understanding the standardization of sport. As can be easily perceived, these organizations were much needed because they could guarantee homogeneity between the different codes or sets of rules. A homogeneous code not only provides the grounds for quantification but also allows athletes to compare their performances with others. This is essential to guarantee the existence of the record, as this is in Guttmann's own words, 'the marvellous abstraction that permits competition not only among those gathered together on the field of sport but also among them and others distant in time and space' $(1978,51)$.

The global appeal of the most popular sports makes it imperative for them to enforce common rules that allow the practitioners to compete on an equal footing and above all, to feel that the sport remains the same no matter where or when it is played. In modern sport governing bodies have become an issue. Sport now occupies a central position in the entertainment industry worldwide, a position that secures huge profits for sports organizations. Meanwhile, many of those organizations are still run on a non-profit basis, as a result of a tradition likely inherited from the amateur condition of sport since its inception. Sport spectators have been able to see internal wars in the most popular sports to gain control of the competitions. Famous teams and players, well aware of their power as global brands, have pushed governing bodies to the brink of extinction. Basketball, cycling, rugby, most notably boxing, and others have experienced, in the last decades, disputes over their governing bodies. The political or economical spheres of these disputes are outside the scope of this article. However, they have been mentioned because of their impact on the quantification. The supranational governing bodies not only function as organizers of competitions but most importantly act as guardians of the essence of the sport, ensuring the historical meaning of the 
achievements and ratifying the records. To illustrate my point we can note the consequences in tennis of the inclusion of professional players from 1968 onwards. Since that time, tennis records must always add the phrase 'before the Open Era' or 'in the Open Era' to substantiate the statement. Governing bodies frequently encounter obstacles derived from the will of companies to have impact on competitions. In swimming the line of progress has been essentially paused since 2008 when sporting manufacturers introduced long-length high-tech swimsuits in the competitions. Since the Swimming World Championship held in Rome in 2009 in particular, only a few male or female swimmers have been able to break new records due to the controversial decision of the Federation Internationale de Natation (FINA) to both validate the marks obtained in Rome and ban the use of the technology from then on. This fact has caused an impasse in swimming history, evident in Shanghai 2011 and London 2012, partially depriving those competitions of their historical significance.

Loland has brought attention to the idea - a dilemma, in his own words - that the pursuit of new records is 'built on the impossible quest for unlimited growth in limited systems' $(2001,130)$. Consequently, he proposes a more sustainable development of sport that could eventually lead to a new sport ideal. From that perspective, quantification is nothing but an ideological standpoint wherein the nature of sport does not necessarily imply the will for records and progress. As a matter of fact, ancient sport had no means of measuring distance or time in a scientifically consistent way and neither was this a preoccupation. In a very illustrative chapter, Guttmann noted that in Ancient Greece metrics of sport played no important role: "whether or not the victor of one Olympiad sent his javelin farther than the one thrown four years earlier seems to have been a matter of indifference' $(1978,49)$. He reminded us that the Greeks had no equivalent word for record. Similarly, the Romans became fascinated with the idea of counting who was first, second and so on, but did not measure it so it could be compared with future or past times or places. Comparably, Otto Penz has also pointed out the significance of geometric and rhythmic patterns rather than numbers in the $19^{\text {th }}$ century sports like tennis-like ballgames where 'the nobility demonstrated a spatial and static ideal of perfection with moderation the main value' (Penz 1990, 159). Bale (1994) contextualized this argument and theorized in a broader sense about modern sports in terms of a passage from aesthetics to measurement. According to this author, the bodycultural tradition has imposed its worldview and supplanted the aesthetical experience 
in which sport was based on some centuries ago. Bale argues that since the late $19^{\text {th }}$ century, coincidentally with the invention of the Modern Olympic Games and its motto, sport has become a pure history of records. This is evident when examining the images proposed by Leni Riefenstahl in the film Olympia. The Nazi filmmaker dodged the modern perspective on sports and went back to the Greek ideals of aesthetics. Body figures and the exaltation of perfection were emphasized to the detriment of more agonistic aspects of the sports and competition.

The standardization of spaces and times to facilitate the pursuing of records has led Henning Eichberg (2002) to coin the term 'sports monoculture', reminiscent of the 'monomyth' employed by Joseph Campbell (1949) to describe the convergence of all the myths in a handful of structures and themes. Sports monoculture undoubtedly is the materialisation of the globalisation in sports, a tendency towards homogeneity and the reduction of local singularities all over the globe. Bale (1994) has postulated that due to its synthetic and technological character, the geography of sports has evolved towards a 'sameness' of spaces, fully interchangeable, that no longer reflects the regional differences of each territory. Every stadium looks the same in what he referred to as the 'placelessness' of sports.

Mass media had already partly eliminated the geographical frontiers well before the digital age. In recent times, even more decisive steps have been taken, stimulated by the global appeal of the top competitions. Spatial boundaries decrease as national competitions expand their area of influence while maintaining their local denomination. The Commissioner of the National Basketball Association (NBA) has said repeatedly that in a few years new European franchises will be joining the league, expanding the American dimension of the competition. The English soccer authorities created the Premier League Asian Trophy in 2003, to be held in rotating Asian countries every two years. This competition has been played so far by the top English clubs plus the national squads from the organizing countries (Malaysia, China, and Thailand). Similarly, the Spanish soccer authorities, as reported by themselves, have entertained the possibility of holding the Super Cup in Beijing, China. Most notably, the main cycling contest in the world, the Tour de France, has crossed its boundaries into other countries like Belgium, Italy, Austria, The Netherlands, Switzerland, Spain, the UK or Ireland, questioning the 
essence of such a promotional-origin media event that has always functioned as a touristic trigger for travellers all over the world to visit and enjoy the French landscape.

However, homogeneity in sport has a sometimes asymmetrical way of manifesting. Space and time are not perceived equally and the geography has been replaced by an emphasis on the chronology. Bale reminds us that space, however accurately quantified, is nothing but a fetish, as no athlete runs in a perfect straight line, eventually covering more distance than they are credited for. He has made the argument that modern sports, rather than increasing the distance have focused on reducing race times. In Paul Virilio's words, 'the tyranny of distances' has given way to 'the tyranny of real time', because, as he would presciently add later, 'space is no longer in geography but in electronics' (Virilio 1997, 115). Time, as Bale has similarly indicated, 'is felt to be in short supply' (1994, 34); a constant corollary of modern societies and has been particularly evident since the convergence of sports and media and the conversion of games into TV shows in the last decades. If we follow this lead we realize that distance always acts as the independent variable in modern sport and that that is not affected by the athletes' performance, while time is the dependent variable that athletes aim to reduce to its minimum value. Instead of how much space can you conquered in a given time, current sports answer the question about how much time can you save in conquering a given space. Motor races, cycling and track \& field are good examples of this. Old competitions like the hour record in cycling have been rendered outdated. In team sports like basketball new rules have been implemented in order to increase the pace of the game while rules to punish slow decisions have been introduced. Speed is power and as Derrida has reminded us 'every invention is the invention of a process of acceleration or at least a new experience of speed' (as cited by Penz 1990, 162). Time is framed as an economic resource, especially in the context of the centrality of mass media in our society. In this article, I would like to illustrate my point by focusing particularly on the temporal aspects of the standardization.

\section{Time conceptualizations of sport}

Let us contemplate for a moment the time models latent in sports practice. In the $20^{\text {th }}$ century, sports scholars who have drawn on Marxist theory have intended to reveal the 
essence of sporting activity by defining it as a by-product of the industrial revolution. According to this view, sport has the function of justifying the established order and always plays an integrating role. For Brohm, sport is nothing but 'a playful representation of the economic competition' $(1978,178)$. Hoch adopted an analogous perspective on the matter and pointed out that the legalized violence contemplated in sports served as a justification for war invasions; and similarly, the possession of the ball symbolized the private property (Hoch, 1972). In this tradition we can include Guttmann as well as other influential scholars like Rigauer (1981). Considered as such, sport must be studied in the context of the leisure activities and spare time; a means of control that bourgeoisie implanted in modern societies to undermine the conflictive ethos of the working class. Thus, since the beginning, research on sport was born around the non-playful elements of it, away from the naivety of thinking of sport solely as a game. The time conceptualization that best suits this approach is the linear time and its core element is the idea of progress. Progress lies embedded in the heart of the quantification and helps to understand the desire for and thrill in record-setting. The direction of sport is always forward and any future sportsman is predicted to achieve further records than his predecessors. World and regional records are broken and that is believed to be the telos of the game. The main advantage of the idea of progress is that it can be easily extrapolated to basically every sphere of the society, that is how deeply ingrained the concept is in the minds of modern citizens. We can progress in school, at work or in our familial situation. This idea was already noted by Ulmann when he developed his 'theory of progress' (Ulmann 1965). More is always better seems to be the adagio and from that perspective, sport embodies the philosophy of progress by means of quantifying it and, more importantly, by celebrating the milestones conquered, that is, the records.

In contrast, circular or cyclical time conception in sport emphasizes the seasonal organization and the recurring elements that compose it. Usually sports competitions are structured following autumn to spring time spans, most notably in European major team sports like soccer or basketball. In the USA, these time spans vary depending on the sport - from autumn to spring in basketball and hockey, spring to winter in baseball and autumn to winter in American football. Globally located sports such as F1 or tennis can prolong their activity for ten or eleven months in a row, always maintaining their annual periodicity. The passage from cyclical time to linear time is condensed in the 
expression 'from ritual to record'. Drawing on Mircea Eliade's work (1959), Guttmann likens the cyclical time to the ritual. The circle represents all that is sacred, the purposeless and eternal return. Dahlen (2012) has also built on this view to reflect on contemporary secular rituals, in which sports play a central role. The circular conception of time in sports, its seasonal structure and annual periodicity, resembles that of the religious festivals. In Agamben's opinion (2007), the ritual transfers the everyday experiences into a separate sphere, a more meaningful and transcendental one. As exposed by Real, 'sports overlie the sacred cycle of mythic time to provide a needed psychic relief from the tedium of Western linear time' $(1975,39)$. Guttmann is even more courageous when he postulates that the pastoral decline in the Western world is rooted precisely in the comedown of the circular conception of time and, for instance, a by-product of this decay is clearly visible in the decline of baseball, a circularly shaped gameplay that symbolizes the search for adventure and the subsequent return home.

The ritualistic view of sporting practice has an opposing stance epitomized in the figure of the record. Records posit a linear conceptualization of time since the path towards progress constitutes its reason for existence. Unlike the religious view condensed in the cyclical ritual time, the linear time of records involves a profane perspective of sports. In this respect, Agamben (2007) has developed very far-reaching ideas around what he calls the secularization - in partial opposition to profanation - of games in modernity. Profanity is a way of escaping the logic of episodic and recurrent events that defines the ritual. Records are the result of an honest belief in the progress, a deeply embedded hope for a better hereafter.

The time conceptualizations proposed so far tend to be holistic views. Notwithstanding this, modernity has brought new models for understanding the passage of time that are particularly appropriate to describe time in sports. Modern societies are believed to be better characterized in terms of liquid or fragmented realities. The metaphor of the 'pointillist time' proposed by Maffesoli (2003) and later endorsed by Bauman (2007) is especially suitable. Building on the painting technique, the pointillist perspective considers modern time to be a fragmented canvas composed of successive spots, defined 'as much by the profusion of ruptures and discontinuities than by the specific content of the spots' $(2007,32)$. Bauman extends his argument and elaborates on the pointillist time by noting that no idea of progress is embedded in it and, furthermore, 
drawing on Siegfried Kracauer and Walter Benjamin's thoughts, he favours the perspective of the non-casual succession of situations, denying the existence of a flow of time that casually connects every dot in the timeline. The case of sporting mega events can help to illustrate this point. Mega events operate as disruptors in the flow of time but at the same time, and paradoxically, serve to 'manage the risk and threats to time structure' and to 'restructure temporality in late modern conditions' (Roche 2003, 107).

A fourth alternative perspective can be utilized to approach the time conceptualization in sport, an approach that can summarize and condense all three. I believe that time in sports is built on elements from the linear conception, exemplified in the idea of progress; on elements from the cyclical conception, as can be seen in its seasonal structure and periodic recurrence; and, on top of that, on elements from the pointillist conception, such as time disruptions like media mega events. In a very different context, Michael Foucault introduced the term 'evolutive time' to depict the disciplinary methods employed in different arenas such as penitentiaries or educational systems. Evolutive time implies a linear scale of time and a form of progress. Simultaneously, it also implies 'a social time of serial, orientated, cumulative type' (Foucault 1991, 160). Additionally, the aspects of linearity and circularity in evolutive time are complemented by a fragmented, pointillist structure that divides the duration into successive or parallel time segments, each of them with a certain end (Penz 1990). The evolutionary metaphor sheds light on the episodic nature of progress in sports, linear but fragmented, while taking into consideration elements of circularity such as comparison or historicity.

\section{Temporal serialization and disruption}

This article attempts to make a convincing case for the crucial consequences of the standardization of sport, combined with the evolutive time conceptualization, for the sports fans in recent times. In order to expand my argument and better characterize the time-origin forces in play in the sporting arena I am willing to conduct a transmutation on the cyclical-linear time axis. The cyclical time, in terms of consumption, may be defined with the word 'familiarity', a commodity already generally known, expected and highly anticipated. The linear time, conversely, is related to 'newness', the feeling 
of uniqueness, originality and the unexpected. Linearity and circularity, newness and familiarity, altogether form an evolutive paradigm for sport. The familiarity is derived from the temporal serialization of sport content which in turn is dependent on its standardization. Meanwhile, the newness comes from the disruption of those familiar aspects. This article inclines towards affirming that the combination those elements very much represents the essence of the sports consumption in modern times.

With regard to its media consumption in particular, sport is a largely serialized commodity. Fans' familiarity with the content they consume is so pervasive that it is questionable whether sports journalists are any longer needed to produce information. This latter statement is somewhat of an exaggeration, but it helps to consider the following. In 2010 some journalistic companies - e.g. The Big Ten Network, partially owned by Fox Networks - began using software that mimics human writing in the recapping of sport games. Narrative Science, the creator, first started the experiments with sports journalism, as it was considered the most 'formulaic, fill-in-the-blank style' (Lohr 2011).

Dunning famously said sport is a 'non-script theatre' (Dunning 1999, 3). The expression accurately reflects the tension between the scripted elements of the show and the opento-improvisation elements of it. A fully theatrical version of sport would have been perceived as a forgery, a deception of the sports ethos. Consequently, information about fixed matches and corrupted sportsmen enervates fans, who then feel deceived in their aspiration to 'have been seeing something real'. The climax of the familiarity, the already known, or the lesser degree of newness, have come, as Verdú had noted (1980), with the Harlem Globetrotters, a basketball exhibition team where the script is all there is. At the same time, the spectators do not need a completely unscripted game for rules and traditions must be observed. The predictability of what is going to happen - the actors, the stage, the judge, the anthem; in one word, the ritualistic and familiar components - needs to be balanced with the unpredictability of the performance, the live events, the outcome; that is, the linearity of human action (Gardiner et al 2006).

This tendency of sports consumers might as well be applied to original television shows. Without digging too deep, the golden age of TV drama can be understood as the audience's enthusiasm for something simultaneously new and familiar, serialized, in 
contrast to film's proposal for an entirely new world every single time. Similarly to TV drama, sports features recurring actors, a crew of characters well known by the audience, whose story unfolds along audience's story. The conjunction of cyclical and linear times permits the media to build up prototypical characters, players whose performance can disappoint or surprise us, depending on the previous narration. Based on a heavily quantified seasonal time structure, professional sport accumulates data from season to season, forming a background of experiences that are still to be interpreted positively or negatively in the light of new evidence. The heroification, a constant habit in today's social and media discourse, and its counterpoint, the villainization, act as episodic, serialized narratives of failure, redemption, success, et cetera. Sporting traditions and rivalries would not be possible if comparable episodes of successive narratives were not delivered to expectant audiences. The recurring passage of time combined with the forward direction, both of them building towards an in crescendo, is what makes the evolutionary metaphor so appropriate.

In this serialized and recurrent time structure, there are indeed time disruptions. They prevent the sporting practice from becoming tedious or monotonous. It is not that they are not expected or anticipated; most importantly they are condensed climatic moments in which the accumulated energies can become a liberated, temporal hiatus that punctuates the uniformity of the passing of time. In my opinion, there are macrostructural and microstructural hiatuses, depending on the sphere in which they develop. Sports mega events can be interpreted as one of those macrostructural time hiatuses. Maurice Roche (2000) called attention to the sports mega events' capacity to structure the public annual calendar. Usually mega events are the final - less likely the initial - stage of a long, periodic competition. The audience hopes to find in them a temporally compressed scene of pent-up emotions whose climax can no longer be delayed or postponed. As time disruptors, they serve to annul, in a way, the timeframe the sport competition inhabits and by doing so, conclude the periodic cycle and restore a new beginning. This phenomenon resembles that attributed to the evolutive time in which time structure is compartmentalized in successive segments, each of them with a certain end (Penz 1990).

Micro-structurally, upon close examination, one may argue that statistics play a similar role as mega events in disrupting time. Any regular consumer of sporting content knows 
that statistics invade every sphere of the games and particularly regarding the media, they have become part of the day-to-day routine of news consumption. As ultimate exponents of the statistical quantification process, records disrupt the timeframe and punctuate its trajectory. Fundamentally, they tell us that 'something unique has occurred', something new, when we were only able to see something familiar or mundane. They integrate in a smaller scale the same features as mega events, marking the culmination of a narrative and its regeneration into the next chapter, and underpinning the overall evolutionary progress composed by leaps forwards and comebacks.

In a largely instant-driven activity like sports consumption, time management can forge either repetitive or memorable instants. Records, thus, cannot be underestimated for they provide an artificial tool with which to differentiate 'the forgettable' from 'the unforgettable' (Roche 2003). The noise produced by the unstoppable flow of information can be somehow sorted and stratified, deciding what is worth remembering. Serialized time must be interrupted, conveniently disrupted so the spectators realize that not everything is meant to sink into oblivion; that some things are to be kept in memory.

\section{Mediated time in sport}

Time conception in sport has been affected in the last decades by an irrefutable phenomenon: its transformation into a TV show (Parente 1977). The obsession with speed and immediacy has been augmented, as time scarcity is inherent to the medium. Sport has become a news-producing factory, open 24/7, and there appear to be no looming signs of decline. In this context, sport has found itself needing to upgrade its 'conditions of visibility' in order to be televisually appealing to a worldwide audience. Increasing technological and human resources in the coverage of sports have been supported by enhanced contextualization tools, which help the spectators make sense of what is occurring on the field.

Media has influenced sport regulation and, particularly, has precipitated decisive changes in its temporal dimension. The pace of play increased in basketball by reducing the time teams are allocated in which to make their play. In cricket and tennis, the 
possibility of endless games has been minimized by implementing tie breaks, for example. In the 1994 Soccer World Cup held in the USA, the organizers asked the FIFA to divide matches into four quarters so that they could insert more frequent time outs (Gardiner and Felix 1995). Media time and sport time try to confluence for the mutual benefit.

Sport, for its part, conditions TV programming and is one the few contents that can arrogate the power of influence the setting of the agenda. In addition, sport moves time slots and affects audience's behaviour in ways no other entertaining industry can afford to do. To illustrate that, we can consider the case of the NBA in Europe. The games are played in the small hours of European Continental time zone. Undoubtedly, the off-peak show attracts a niche of audience who is willing to accept sleep deprivation in exchange for a high quality TV programme (Boyle and Haynes 2000). In recent times, European soccer competitions, especially the English Premier League, have advanced their weekend matches in order to accommodate Asian soccer fans in a more convenient time slot. This capacity of sports to alter spectators' habits is arguably unique. As a matter of fact, sport has turned out to be quite an invasive species in the media ecology. In bygone days, soccer matches used to take place on Sundays, then on Saturday and Sundays. Nowadays, soccer has expanded to the period from Tuesday to Monday, with the exception of Fridays, that are widely the day without soccer. For the sake of the evolutionary metaphor, we could say that the rest of the sports in soccer-dominated countries try to find the uncolonized spots, being that the case of niche sports that have moved to less crowded gaps of the calendar. Most notably, the Handball World Championship has disputed since 2001 its tournament in January while other sports have decided to hold their championships in September - Volleyball or Basketballwith every single one of them opting out of July: the month of soccer mega events.

Sport and media, working side by side, are responsible for the configuration of the annual public calendar of sports events. This calendar has several layers as it macrodistributes yearly mega events and large competitions sorted by seasons while microdistributing games sorted by weekdays and time spots. One of the issues both face when arranging such a calendar and timetable are the death moments, the anti-climatic episodes that logically follow every climax. They cannot afford to lose audience attention and in that attempt, they mitigate that risk by creating new/familiar talking 
points that anticipate and advance the future events. As any committed fan could confirm, sport consumption is a cyclical activity, accentuated by linear climatic endings and a never-ending narrative of failures and successes.

New media have brought to the fore new ways of consuming sport and, in doing so, they have caused consequences for the temporal setup of sport. If we remember Ingham's words (2004), he referred to sport as a 'serialized civic ritual', a sharing ritual whose contemplation becomes a get-together show (Magnane 1966) in which future collective memory generation plays a fundamental part in advance. As a case in point, many current devices have made it possible to drastically enliven the spectators' sharing experience and influence the time and space of the consumption. For instance, second screens have facilitated the multitasking of the spectators, which can be virtually present in different stadia simultaneously, and all the while engage in Twitter discussions. More importantly, social media have emphasized the desire for live commenting, enhancing the experience of 'watching together' beyond the realm of the public house or the living room. Quantification has contributed to this experience by introducing data visualization and real time statistics. Also, presenting new ways of online betting that allow more engaging — more invested, so to say — ways of experiencing live sports events.

Yet, one may argue that figures and records not only serve the media as performance measurements but, above all, they function as discursive constructs. Loland (2001) has divided modern sports into three categories: record sports, which have exact performance measurement and exact standardized frameworks - track \& field or swimming-; quasi-record sports, with one of the two aforementioned characteristics missing - a marathon, for instance, wherein there is no standard framework as they are held in different cities; and games, which are no record sports, according to the author. The most popular sports - namely, soccer, basketball or tennis - fit in this third category, in which 'talk of records makes little sense' (2001, 128). However, the media frequently finds it sensible to talk about records in those sports, praising the best player of a generation or the best team in contention. This argument could lend to support the idea that records are discursive resources, rather than factual, for the media because they help them to shape, punctuate and measure out the narratives of sport. 


\section{Final Considerations}

This article began by citing Richard Giulianotti, who envisioned sport quantification as a means of reducing 'complex events into intelligible, manageable information for mass audiences' (Giulianotti 2005, 21). In a different context, David Rowe had stated a few years earlier that sport was 'readily translatable as the Esperanto of mediatized entertainment' (Rowe 2003, 286). I have reunited these two quotes because I believe they both share a common understanding of the basics of sport in modern days. The quantification, a largely mathematical world, has paralleled Esperanto's contribution by providing valuable communicative elements that can be equally appreciated by diverse audiences all around the world. From that perspective, the sports quantification process envisaged by Guttmann in the late 1970s has proved to be utterly successful in predicting the globalization of sport as an international language of exchange, a massively understandable Esperanto reduced to its simplest and most visible aspects.

The monoculture of sport (Eichberg 2002) has caused a tendency towards the homogeneity of its forms, both temporal and spatial. The standardization that enabled the quantification in sport has multiple consequences in terms of time conceptualization. I have briefly examined a few of them, arguing that any time conception willing to accurately describe temporality in sport must take into account both the cyclical and the linear facets of it. The ritual and the record, the known and the uncertain, familiarity and newness, all account for the singular characteristics of professional sport and fan consumption. The implications of the results of the aforementioned have been explored essentially in two complementary areas: the time disruptions and serializations, and the mediated time in sport. In essence, I have argued throughout these pages that the quantification and pursuit of records have boosted statistical awareness and most notably, the fixation of a public annual - and monthly and weekly — calendar as well as a daily timetable.

However, the cost of this monoculture could be counterbalanced in the near future by the emergence of alternative sports targeting niche audiences. Risk or extreme sports, for instance, associated with modern consumer lifestyles, might reintroduce the ideals of aesthetics and creativity to the detriment of quantification and records. This could potentially lead to a more diverse sport ecology and force to reconsider the validity of 
Guttmann's perspective, or at least its centrality. Television and the Internet, and lately the social media, are taking into account the importance of this phenomenon. Nevertheless, in the context of a highly fragmented media consumption of modern spectators, quantification and records, and their ability to dictate the unique, the mustsee and the unforgettable, still play a fundamental role in so far as they function as timenegotiators. As consumers are given the choice of experiencing cultural products at their own pace, thus fragmenting the act of consumption, sport still serves as one of the few remaining resources that can synchronize the audience's habits, gathering large amounts of global spectators in order to carry out a tradition on the brink of extinction: 'watching the same at the same time' (Whannel 2009).

\section{References}

AGAMBEN, G. 2007. Profanations. New York: Zone Books.

BALE, J. 1994. Landscapes of modern sport. New York: Leicester University Press.

BAUMAN, Z. 2007. Consuming life. Cambridge: Polity Press.

BOYLE, R., \& HAYNES, R. 2000. Power Play: Sport, Media and Popular Culture. London: Longman.

BROHM, J.-M. 1978. Sport, a prison of measured time. London: Ink Link Limited.

CAMPBELL, J. 1949. The Hero with a thousand faces. London: Fontana Press.

DALHEN, P. 2012. An exemplary model. The religious significance of the Brann 2007 Norwegian football championship as told by the media. In We love to hate each other. Mediated football fan culture, ed. R. Krovel, \& T. Roksvold, 63-82. Goteborg: Nordicom.

D'HEER, E., COURTOIS, C., \& PAULUSSEN, S. 2012. Everyday life in (front of) the screen: The consumption of multiple screen technologies in the living room context. EuroiTV'12 - Proceedings of the 10th European Conference on Interactive TV and Video , 195-198.

DUNNING, E. 1999. Sport matters: Sociological studies of sport, violence and civilization. London: Routledge.

EICHBERG, H. 2002. Body Cultures: Essays on Sport, Space \& Identity by Henning Eichberg. London: Routledge.

ELIADE, M. 1959. The sacred and the profane. Orlando: Harcourt Brace Jovanovich.

FOUCAULT, M. 1991. Discipline and punish: the birth of the prison. London: Penguin Books .

GARDINER, S., \& FELIX, A. 1995. Juridification of the Football Field: Strategies for Giving Law the Elbow. Marquette Sports Law Review 5, no. 1: 189-219.

GARDINER, S., JAMES, M., O'LEARY, J., WELCH, R., BLACKSHAW, I., \& BOYES, S. 2006. Sports law. Sydney: Cavendish.

GIULIANOTTI, R. 2005. Sport. A critical sociology. Cambridge: Polity Press.

GUTTMANN, A. 1988. A whole new ball game: An interpretation of American sports. Chapel Hill: The University of North Carolina Press. 
GUTTMANN, A. 1978. From ritual to record. New York: Columbia University Press.

HOCH, P. 1972. Rip off the big game. New York: Anchor books.

INGHAM, A. G. 2004. The Sportification Process: A Biographical Analysis Framed by the Work of Marx, Weber, Durkheim and Freud. In Sport and Modern Social Theorists: Theorizing Homo Ludens, ed. R. Giulianotti, 11-32. London: Palgrave Macmillan.

LOHR, S. (2011). In case you wondered, a real human wrote this column. The New York Times . September 10, 2011

LOLAND, S. 2001. Record Sports: An Ecological Critique and a Reconstruction. Journal of the Philosophy of Sport 28: 127-139.

MAFFESOLI, M. 2003. L'Instant éternel. Le retour du tragique dans les sociétés postmodernes. Paris: La table ronde.

MAGNANE, G. 1966. Sociología del deporte. Madrid: Península.

PARENTE, D. E. 1977. The Interdependence of Sports and Television. Journal of Communication 27, no. 3: 128-132.

PENZ, O. 1990. Sport and speed. International Review for the Sociology of Sport 25, no. 2: 157-167.

REAL, M. 1975. Super Bowl: Mythic spectacle. Journal of Communication 25, no. 1: 31-43.

RIGAUER, B. 1981. Sport and work. New York: Columbia University Press.

ROCHE, M. 2000. Mega-events and modernity: Olympics and Expos in the growth of global culture. London: Routledge.

ROCHE, M. 2003. Mega-events, time and modernity on time structures in global society. Time \& Society 12, no. 1: 99-126.

ROWE, D. 2003. Sport and the Repudiation of the Global. International Review for the Sociology of Sport 38, no. 3: 281-294.

ULMANN, J. 1965. De la gymnastique aux sports modernes. Paris: Presses universitaires de France.

VERDÚ, V. 1980. El fútbol: mitos, ritos y símbolos. Madrid: Alianza.

VIRILIO, P. 1997. Pure war. New York: Semiotext(e).

WHANNEL, G. 2009. Television and the Transformation of Sport. The Annals of the American Academy 625: 205-218. 